\title{
Article \\ Single Particle Combustion of Pre-Stressed Aluminum
}

\author{
Kevin J. Hill ${ }^{1}{ }^{\circledR}$, Michelle L. Pantoya ${ }^{1}{ }^{(0)}$, Ephraim Washburn ${ }^{2}$ and Joseph Kalman ${ }^{3, *}$ \\ 1 Department of Mechanical Engineering, Texas Tech University, Lubbock, TX 79409, USA; \\ kevin.hill@ttu.edu (K.J.H.); michelle.pantoya@ttu.edu (M.L.P.) \\ 2 Combustion Science and Propulsion Research Branch, Naval Air Warfare Center Weapons Division, \\ 1 Administration Circle, China Lake, CA 93555, USA; ephraim.washburn@navy.mil \\ 3 Department of Mechanical and Aerospace Engineering, California State University, Long Beach, Long Beach, \\ CA 90840, USA \\ * Correspondence: joseph.kalman@csulb.edu
}

Received: 1 May 2019; Accepted: 22 May 2019; Published: 29 May 2019

\begin{abstract}
An approach for optimizing fuel particle reactivity involves the metallurgical process of pre-stressing. This study examined the effects of pre-stressing on aluminum (Al) particle ignition delay and burn times upon thermal ignition by laser heating. Pre-stressing was by annealing $\mathrm{Al}$ powder at $573 \mathrm{~K}$ and quenching ranged from slow (i.e., $200 \mathrm{~K} / \mathrm{min}$ ) identified as pre-stressed (PS) $\mathrm{Al}$ to fast (i.e., $900 \mathrm{~K} / \mathrm{min}$ ) identified as super quenched (SQ) Al. Synchrotron X-ray Diffraction (XRD) analysis quantified an order of magnitude which increased dilatational strain that resulted from PS Al and SQ Al compared to untreated (UN) Al powder. The results show PS Al particles exhibit reduced ignition delay times resulting from elevated strain that relaxes upon laser heating. SQ Al particles exhibit faster burn times resulting from delamination at the particle core-shell interface that reduces dilatational strain and promotes accelerated diffusion reactions. These results link the mechanical property of strain to reaction mechanisms associated with shell mechanics that explain ignition and burning behavior, and show pre-stressing has the potential to improve particle reactivity.
\end{abstract}

Keywords: aluminum; stress; strain; laser ignition; reaction mechanism; solid fuels

\section{Introduction}

Aluminum (Al) is an important solid fuel for propulsion and pyrotechnic applications because of its high $\left(85 \mathrm{GJ} / \mathrm{m}^{3}\right)$ stored chemical energy, and its burning behavior at a range of particle sizes and environments are of great interest. For propulsion applications, ignition delay and burn times of $\mathrm{Al}$ particles are important to understand because reduced $\mathrm{Al}$ particle burn time and ignition delay can provide added energy to facilitate propellant surface burning regression or reduce particle agglomeration on the burning propellant surface [1]. A promising approach to improve Al particle ignition delay and burn time is pre-stressing [2,3]. Pre-stressing is the intentional creation of favorable stresses in core-shell Al particles via annealing and quenching. The induced stresses place the shell in compression, and change the dynamics of shell failure during ignition and subsequent combustion. Considerable studies have been undertaken on pre-stressed Al particles under impact [2,3], but no studies have been conducted on the combustion of pre-stressed $\mathrm{Al}$ particles under thermal loads for single particle conditions.

Single particle combustion of Al has a long history of experimental and theoretical work [4-9]. Several systems exist for creating well-dispersed dust clouds of single particles for combustion studies. Methods include fluidized bed elution [10,11], vortex mixing [12], electrostatic aerosolization [8,9], and others $[13,14]$. The goal of each system is to create clouds of particles with stable concentrations 
and particle sizes. These systems have not been used to study pre-stressed $\mathrm{Al}$ particles. In this study, $800 \mu \mathrm{m}$ diameter glass beads were used as a fluidizing medium to create a low-concentration stream of 3-4.5 $\mu \mathrm{m}$ diameter Al particles (particle size has previously been reported in [15]). The eluted particles were then heated and ignited with a $600 \mathrm{~W} \mathrm{CO}_{2}$ laser. The objective was to examine the influence of pre-stressing on ignition delay and burn times under thermal initiation conditions.

\section{Materials and Methods}

Aluminum particles (3-4.5 $\mu$ m diameter, Alfa Aesar, Haverhill, MA, USA) were treated through an annealing and quenching process that is detailed elsewhere [2,3] but summarized here. Pre-stressing aluminum (PS Al) particles was undertaken by heating at $10 \mathrm{~K} / \mathrm{min}$ to $573 \mathrm{~K}$, holding isothermally for $15 \mathrm{~min}$, and quenching at a rate of $200 \mathrm{~K} / \mathrm{min}$ via a TA Instruments Q800 DMA (dynamic mechanical analyzer, TA Instruments, New Castle, DE, USA). For faster quenching, super quenched aluminum (SQ Al) powders were placed in a custom water-tight quenching chamber, held isothermally at $573 \mathrm{~K}$ for $15 \mathrm{~min}$ in a Ney bake-out oven, and quenched at a rate of $900 \mathrm{~K} / \mathrm{min}$ via a brine bath composed of water, salt, surfactant, and dish soap [3]. It is notable that the powder was never in direct contact with the liquid solution used for quenching.

\subsection{Synchrotron X-Ray Diffraction (XRD) Measurements}

The PS Al, SQ Al, and untreated $\mathrm{Al}(\mathrm{UN} \mathrm{Al})$ powders were analyzed using Synchrotron XRD at the Advanced Light Source facility at Lawrence Berkeley National Laboratory on beamline 12.3.2. This beamline uses a micron focused synchrotron X-ray beam to determine dilatational strain and a white micro-beam technique $[16,17]$ to determine dilatational strain data that was previously reported $[3,15,18,19]$.

\subsection{Single Particle Reactive Characterization}

A 1-g powder sample of $\mathrm{PS} \mathrm{Al}, \mathrm{SQ} \mathrm{Al}$, or $\mathrm{UN} \mathrm{Al}$ powder was loaded into the particle injector shown Figure 1a and composed of a $5.08 \mathrm{~cm}$ by $30.48 \mathrm{~cm}$ vacuum flange filled with $800 \mu \mathrm{m}$ of glass beads at a weight ratio of 100:1 beads to Al powder. Dry shop air was passed through the powder bed at a rate of $14.2 \mathrm{~L} / \mathrm{min}$, and the eluted particles were passed through the beam path of a $600 \mathrm{~W}$ $\mathrm{CO}_{2}$ laser focused down to a $200 \mu \mathrm{m}$ spot size as shown in Figure 1b. The laser was programed to operate in $1 \mathrm{~ms}$ pulses with $10 \mathrm{~ms}$ between pulses, for a 10\% duty cycle. A Photron SA-Z with a K2 microscopic lens (Infinity, Centennial, CO, USA) recording at 30,000 frames/s with a resolution of 1024 $\times 1024$ pixels (64.2 pixels $/ \mathrm{mm}$ ) was triggered with each laser pulse to record particle ignition and combustion. The mean particle velocity was approximately $5.3 \mathrm{~m} / \mathrm{s}$ (based on volumetric flow rate) with an observation time of $2 \mathrm{~ms}$. An in-house MATLAB ${ }^{\circledR}$ script analyzed burn time and ignition delay data by tracking particle residence time and location of first light respectively, as shown in Figure $1 \mathrm{~b}$. 


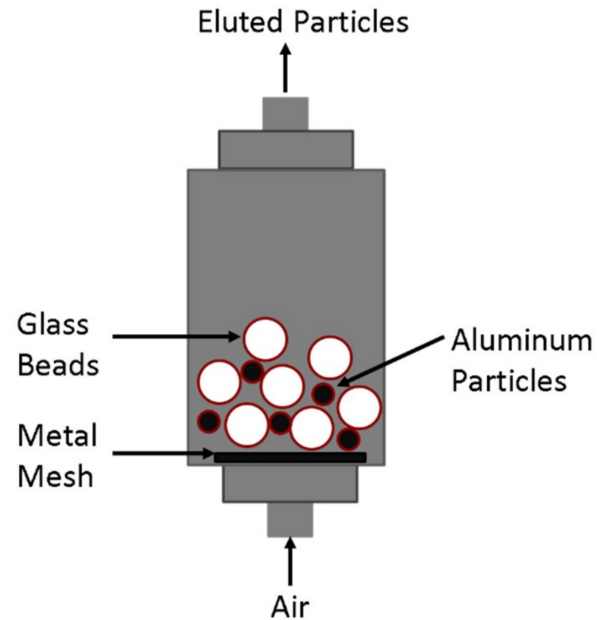

(a)

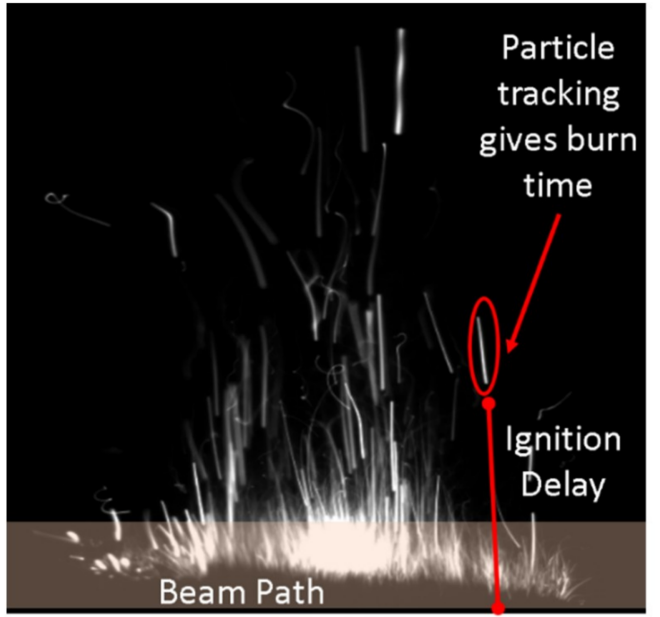

(b)

Figure 1. (a) Schematic of particle injection system showing Al particles and glass beads used to elute Al particles into the laser beam path. (b) Photograph of untreated aluminum powder (UN Al) particle burning upon exposure to laser beam representing burn time and ignition delay measurements.

\section{Results}

Figure 2 shows cumulative probability plots for burn time and ignition delay of each material tested and provides statistical insight for large (>5000 particles) sample sizes. The apparent discretization on the burn time plot (Figure 2a) is a result of low time resolution due to a relatively slow frame rate, while the smoother ignition delay plot (Figure $2 \mathrm{~b}$ ) is a result of large spatial resolution. The scatter in the data is a result of the polydisperse particles endemic to the Al powder used.

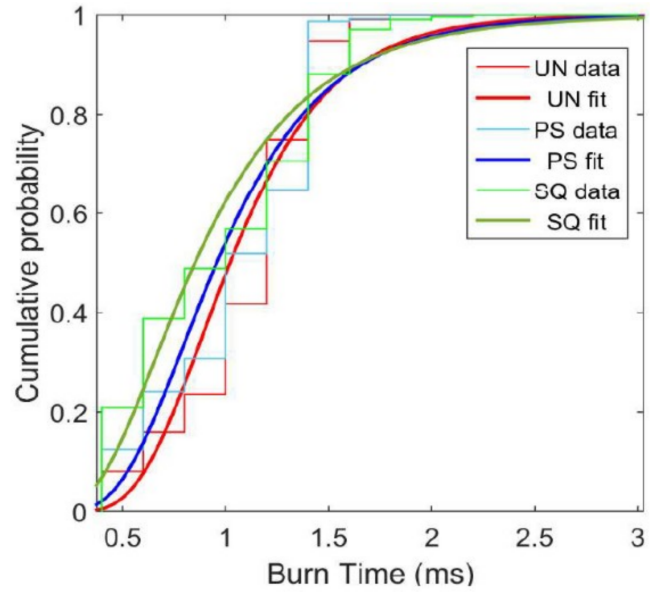

(a)

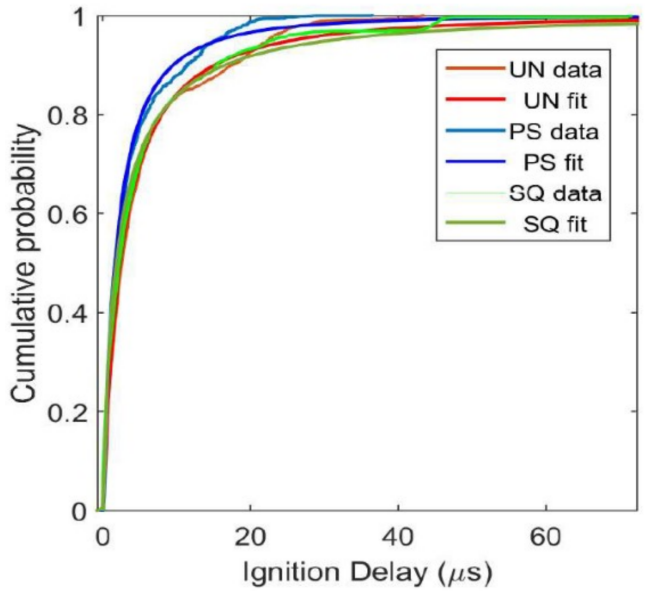

(b)

Figure 2. Cumulative probability of: (a) burn time and (b) ignition delay for untreated Al powder (UN Al), pre-stressed $\mathrm{Al}$ powder (PS Al) and super-quenched $\mathrm{Al}$ powder (SQ Al).

Table 1 shows the true mean, average for all data within two standard deviations (2 SD), average for all data within three standard deviations (3 SD), and the median for all data, as well as percent differences from UN Al for the PS Al and SQ Al particles. The SQ Al has the fastest burn time, followed by PS Al. The largest percent decrease in burn time compared to UN Al for both PS Al and SQ Al occur when only two standard deviations of data are considered, indicating outliers in the data that may be a function of agglomeration. The PS Al has the largest decrease in ignition delay, with little difference depending on how many standard deviations were considered (i.e., there are few outliers in this data). 
Table 1. Average and median burn time and ignition delay values within different standard deviation (SD) bounds (with \% differences from the UN particles).

\begin{tabular}{ccccc}
\hline \multirow{2}{*}{ Particle Type } & Mean (All Data) & Average (2 SD) & Average (3 SD) & Median \\
\cline { 2 - 5 } & \multicolumn{4}{c}{ Burn Time (ms) } \\
\hline UN & 1.08 & 1.37 & 1.08 & 1.2 \\
PS & 1.04 & 1.03 & 1.03 & 1 \\
SQ & 0.96 & 0.95 & 0.96 & 1 \\
\hline Particle Type & \multicolumn{5}{c}{ Ignition Delay Time ( $\mu$ s) } \\
\hline UN & 13.79 & 9.88 & 12.42 & 6.42 \\
PS & 9.37 & 6.80 & 8.29 & 4.26 \\
SQ & 14.18 & 10.16 & 10.80 & 5.59 \\
\hline Particle Type & \multicolumn{5}{c}{ Burn Time \% Decrease from UN Al } \\
\hline PS & 4.37 & 24.86 & 4.48 & 16.67 \\
SQ & 11.34 & 30.67 & 11.47 & 16.67 \\
\hline Particle Type & \multicolumn{5}{c}{ Ignition Delay Time \% Decrease from UN Al } \\
\hline PS & 32.11 & 31.15 & 33.30 \\
SQ & -2.82 & -2.81 & 13.07 & 12.87 \\
\hline
\end{tabular}

\section{Discussion}

Figure 2 and Table 1 show modest improvement in burn time for PS Al and SQ Al compared to UN Al particles. The SQ Al particles show little difference in ignition delay time compared to the UN Al, indicating that combustion begins after a similar amount of laser energy was absorbed. However, PS Al particles show a substantially shorter ignition delay time (60\% of the particles ignited $30.6 \%$ faster and $90 \%$ ignited $36.3 \%$ faster than UN Al) (Figure 2). A shorter ignition delay time could occur for larger particle sizes in the population (sizes that require more energy to ignite) if some energy release occurs due to internal stress release during heating [2,3]. However, calculating the strain energy for a single $3.5 \mu \mathrm{m}$ PS Al particle yields $7 \times 10^{-15} \mathrm{~J}$, while the energy required to heat the same particle to the melting temperature of alumina is approximately $1 \times 10^{-7} \mathrm{~J}$.

Synchrotron XRD measurements in Table 2 for UN Al, PS Al and SQ Al particles show an increase in dilatational strain within the core-shell particle that results from pre-stressing. The UN Al particles show nearly negligible residual strain, indicating that the process of pre-stressing elevates the strain of the Al particle by an order of magnitude. However, SQ Al particles produce a measurably lower dilatational strain compared with PS Al despite the theoretical prediction that faster quenching will elevate the strain [3]. The reason for the decreased dilatational strain under super quenching conditions has been modeled as delamination at the core-shell particle interface that relaxes induced stresses and reduces dilatational strain within the particle. Delamination at the core-shell interface is predicted to be on the order of $52 \%$ for $3-4.5 \mu \mathrm{m}$ in diameter of SQ Al particles [3]. Figure 2 shows PS Al particles with elevated dilatation strain (Table 2) have shorter ignition delay time than the other samples. In contrast, SQ Al and UN Al have lower strain (Table 2) and therefore, less added energy to reduce ignition delay time.

Table 2. Synchrotron XRD measurements of dilatational strain for 3-4.5 $\mu \mathrm{Al}$ particles [3].

\begin{tabular}{cc}
\hline Material & Dilatational Strain \\
\hline UN Al & $1.5 \times 10^{-6}$ \\
PS Al & $9.23 \times 10^{-5}$ \\
SQ Al & $5.7 \times 10^{-5}$ \\
\hline
\end{tabular}

The SQ Al particles had the shortest burn times (11.8\% faster than UN Al at $60 \%$ of total particle population), with burn times for all particle treatments converging at $90 \%$ of the total particle population 
(Figure 2). Shorter burn times indicate a reduced diffusion barrier in the SQ Al particles that may be attributed to shell delamination [3], which could lead to cracking in the alumina shell. Shell cracking would reduce the barrier for diffusion reactions as evidenced by the shorter burn times.

Aluminum particles inherently include a surface hydration layer surrounding the $\mathrm{Al}_{2} \mathrm{O}_{3}$ passivation shell. Annealing and quenching the Al particles may alter the surface hydration layer and affect surface energy forces that promote agglomeration. It is assumed that after annealed and quenched particles were exposed to ambient conditions, they would naturally rehydrate. Visual inspection of the $\mathrm{Al}$ powders reveals no apparent differences in agglomeration behavior that would contribute to the behaviors observed in Figure 2.

The results presented in Figure 2 are consistent with previous work on pre-stressed particles under impact loads [3]. Hill et al. [3] reported that PS Al particles demonstrate higher pressurization rates than SQ Al particles under impact loads, and is similar to the reduced ignition delay times of PS Al particles shown in Figure 2 compared with both SQ Al and UN Al particles. Additionally, the reduced particle burn times of SQ Al particles are consistent with the higher peak pressures and increased combustion completeness of SQ Al particles shown in Hill et al. [3].

\section{Conclusions}

Aluminum particles have been pre-stressed using two different quenching treatments that increase their dilatational strain. Quenching slowly elevates the particle strain and quenching quickly promotes delamination at the core-shell particle interface and reduces particle strain. Both quenching treatments produce $\mathrm{Al}$ particles at elevated strain compared with untreated $\mathrm{Al}$. The mechanical alteration of the $\mathrm{Al}$ particles affects their ignition and burning behavior when subjected to a $\mathrm{CO}_{2}$ laser beam. Pre-stressed $\mathrm{Al}$ particles quenched slowly (PS Al) exhibit reduced ignition delay times while pre-stressed particles quenched quickly (SQ Al) exhibit reduced burn times. Elevated strain energy may contribute to a reduction of energy needed to ignite the particles thereby leading to reduced ignition delay time. Shell-core delamination associated with SQ Al particles facilitates diffusion reactions thereby reducing burn times. Altering the mechanical properties of the shell-core particles alters their reaction mechanism. This study links reactive behavior with mechanistic understanding associated with the mechanical property of dilatational strain.

Author Contributions: K.J.H. performed the experiments, analyzed the data, and wrote the initial draft. M.L.P., E.W., and J.K. supervised and advised on the work, reviewed, edited, and provided funding support for this effort. K.J.H. and J.K. designed the experiment.

Funding: This research received funding from Office of Naval Research under ONR contract N00014-16-1-2079 and N00014-19-1-2082 from program managers, Chad Stoltz and Matthew Beyard. This work was partially sponsored by the Naval Air Systems Command (NAVAIR) Inter Laboratory Independent Research (ILIR) Program, managed by the Office of Naval Research (ONR) under the Naval Science and Technology for America's Readiness (N*STAR) Program. K.H. was supported by the Naval Research Enterprise Internship Program (NREIP) and J.K. was supported partially by California State University, Long Beach Academic Affairs for this work. The strain measurements were supported by the Office of Basic Energy Sciences, Materials Science Division, of the U.S. 440 Department of Energy under Contract No. DE-AC02-05CH11231 at LBNL.

Conflicts of Interest: The authors declare no conflicts of interest.

\section{References}

1. Kalman, J.; Demko, A.R.; Varghese, B.; Matusik, K.E.; Kastengren, A.L. Synchrotron-based Measurement of Aluminum Agglomerates at Motor Conditions. Comb Flame 2018, 196, 144-147. [CrossRef]

2. Hill, K.J.; Warzywoda, J.; Pantoya, M.L.; Levitas, V.I. Dropping the Hammer: Examining Impact Ignition and Combustion Using Pre-stressed Aluminum Powder. J. Appl. Phys. 2017, 122, 125102. [CrossRef]

3. Hill, K.J.; Tamura, N.; Levitas, V.I.; Pantoya, M.L. Impact Ignition and Combustion of Micron-scale Aluminum Particles Pre-stressed with Different Quenching Rates. J. Appl. Phys. 2018, 124, 115903. [CrossRef]

4. Friedman, F.; Maček, A. Ignition and Combustion of Aluminum Particles in Hot Ambient Gases. Comb Flame 1962, 6, 9-19. [CrossRef] 
5. Washburn, E.B.; Webb, J.A.; Beckstead, M.W. The Simulation of the Combustion of Micrometer-sized Aluminum Particles with Oxygen and Carbon Dioxide. Comb Flame 2010, 157, 540-545. [CrossRef]

6. Allen, D.; Krier, H.; Glumac, N. Heat Transfer Effects in Nano-aluminum Combustion at High Temperatures. Comb Flame 2014, 161, 295-302. [CrossRef]

7. Lynch, P.; Krier, H.; Glumac, N. A Correlation for Burn Time of Aluminum Particles in the Transition Regime. Proc. Combust. Inst. 2009, 32, 1887-1893. [CrossRef]

8. Mohan, S.; Trunov, M.A.; Dreizin, E.L. Heating and Ignition of Metallic Particles by a $\mathrm{CO}_{2}$ Laser. J. Prop. Power 2008, 24, 199-205. [CrossRef]

9. Gill, R.J.; Mohan, S.; Dreizin, E.L. Sizing and Burn Time Measurements of Micron-sized Metal Powders. Rev. Sci. Instrum. 2009, 80, 064101. [CrossRef]

10. Prenni, A.J.; Siefert, R.L.; Onasch, T.B.; Tolbert, M.A.; Demott, P.J. Design and Characterization of a Fluidized Bed Aerosol Generator: A Source for Dry, Submicrometer Aerosol. Aerosol Sci. Technol. 2000, 32, 465-481. [CrossRef]

11. Boucher, R.F.; Lua, A.C. A Stable, High-concentration, Dry Aerosol Generator. J. Aerosol Sci. 1982, 13, 499. [CrossRef]

12. Glass, M.; Kennedy, I.M. An Improved Seeding Method for High Temperature Laser Doppler Velocimetry. Comb Flame 1977, 29, 333-335. [CrossRef]

13. Cashdollar, K.L.; Chatrathi, K. Minimum Explosible Dust Concentrations Measured in 20-L and $1 \mathrm{~m}^{3}$ Chambers. Comb Sci. Technol. 1993, 87, 157-171. [CrossRef]

14. Kalejaiye, O.; Amyotte, P.R.; Pegg, M.J.; Cashdollar, K.L. Effectiveness of Dust Dispersion in the 20-L Siwek Chamber. J. Loss Prevent. Proc. Ind. 2010, 23, 46-59. [CrossRef]

15. McCollum, J.; Pantoya, M.L.; Tamura, N. Improving Aluminum Particle Reactivity by Annealing and Quenching Treatments: Synchrotron X-ray Diffraction Analysis of Strain. Acta Mater. 2016, 103, 495-501. [CrossRef]

16. Kunz, M.; Tamura, N.; Chen, K.; MacDowell, A.A.; Celestre, R.S.; Church, M.M.; Fakra, S.; Domning, E.E.; Glossinger, J.M.; Kirschman, J.L.; et al. A Dedicated Superbend X-ray Microdiffraction Beamline for Materials, Geo-, and Environmental Sciences at the Advanced Light Source. Rev. Sci. Instrum. 2009, 80, 035108. [CrossRef] [PubMed]

17. Tamura, N. Strain and Dislocation Gradients from Diffraction: Spacially-Resolved Local Structure and Defects; Barabash, R., Ice, G., Eds.; Imperial College Press: London, UK, 2014; p. 125.

18. Levitas, V.I.; McCollum, J.; Pantoya, M.L. Pre-stressing Micron-scale Aluminum Core-shell Particles to Improve Reactivity. Sci. Rep. 2015, 5, 7879. [CrossRef] [PubMed]

19. Levitas, V.I.; McCollum, J.; Pantoya, M.L.; Tamura, N. Stress Relaxation in Pre-stressed Aluminum Core-Shell Particles: X-Ray Diffraction Study, Modeling, and Improved Reactivity. Comb. Flame 2016, 170, 30-36. [CrossRef]

(C) 2019 by the authors. Licensee MDPI, Basel, Switzerland. This article is an open access article distributed under the terms and conditions of the Creative Commons Attribution (CC BY) license (http://creativecommons.org/licenses/by/4.0/). 